2021:6(6):219-223

http://ojs.uho.ac.id/index.php/JIA

doi: http://dx.doi.org/10.37149/JIA.v6i6.22655

\title{
PERANAN KELOMPOK TANI DALAM PENINGKATAN PENDAPATAN (Studi Kasus KWT Usaha Bunda Setinjau Alam Desa Simpang Talang Tembago Kecamatan Jangkat Timur Kabupaten Merangin)
}

\author{
Pitriani $^{\left.1^{*}\right)}$, Fajar Yuliardi ${ }^{1}$, Evo Afrianto ${ }^{1)}$ \\ ${ }^{1}$ Program Studi Agribisnis, Fakultas Pertanian, Universitas Muara Bungo,Jl. Pendidikan, RT. 10 RW. 02 No 10 \\ Kelurahan Sungai Binjai. Kecamatan Bathin III. Kabupaten Bungo, \\ Jambi 37228, Indonesia \\ *Corresponding author: pitrianianto@yahoo.com \\ To cite this article: \\ Pitriani, P., Yuliardi, F., \& Afrianto, E. (2021). Peranan Kelompok Tani dalam Peningkatan Pendapatan (Studi \\ Kasus KWT Usaha Bunda Setinjau Alam Desa Simpang Talang Tembago Kecamatan Jangkat Timur Kabupaten \\ Merangin). JIA (Jurnal IImiah Agribisnis) : Jurnal Agribisnis dan IImu Sosial Ekonomi Pertanian, 6(6), 219 - 223. \\ doi:http://dx.doi.org/10.37149/jia.v6i6.22655
}

Received: December 24, 2021; Accepted: December 30, 2021; Published: December 31, 2021

\begin{abstract}
This study aimed to determine the role of farmer groups in increasing coffee farmers' income and determine the level of farmers' income. This research was carried out in Simpang Talang Tembago Village, Jangkat Timur District, Merangin Regency on July 1-30, 2020. This location selection was carried out purposively considering that Simpang Talang Tembago Village is one of the significant agricultural developments in the coffee plantation sector in the District. Merangin Jambi Province is the only village with a Farmer's Group that played an important role when named the best coffee product in Indonesia at the International Coffee day 2019 event. The research method used was the Survey method which directly interviewed the management and group members. Farmer. Interviews in this study were conducted with all farmer group members, which amounted to 24 people with purposive sampling and were given questions or questionnaires. The data were analyzed using a Likert Scale. The results of the research show that the role of farmer groups in increasing the income of coffee farmers consists of 3 roles, namely social media or extension media that is lively, natural, and dynamic; tools to achieve change with the aim of agricultural extensionists; a place or container for a pure and healthy statement of aspirations following the wishes of the farmers themselves. From the research results, the role of farmer groups in influencing the income of high coffee farmers is 1035 with a score of 720-1080, and a high level of income is 505 , with a category score of 384-576.
\end{abstract}

Keywords: role; income level; KWT Bunda Setinjau Alam Business

\section{PENDAHULUAN}

Pembangunan pertanian atau pengelolaan lahan, baik yang dilakukan oleh pemerintah maupun swasta, sangat dipengaruhi oleh keberadaan dan ketergantungan masyarakat petani terhadap sumber daya alam. Dengan kata lain, tujuan pengelolaan lahan dan pengelolaan hasil tanaman kopi yang maksimal tidak akan tercapai jika tidak memperhatikan keterlibatan dan kesejahteraan masyarakat. Kopi merupakan salah satu komoditas unggulan yang diproyeksikan dapat berperan dalam devisa negara, pendapatan petani, penciptaan lapangan kerja, pertumbuhan agribisnis dan agroindustri, serta pembangunan daerah (Hasan, 2011).

Pohon kopi merupakan salah satu komoditas perkebunan nasional yang sangat penting dalam perekonomian Indonesia. Posisi ini mungkin sebagai sumber uang bagi petani atau sebagai sumber peluang kerja. Petani kini memiliki lebih banyak pilihan berkat pengelolaan komoditas kopi, yang juga telah membuka lapangan kerja bagi para pedagang, pengumpul, dan eksportir, serta karyawan perkebunan besar dan personel sektor pengolahan kopi. Kopi (Coffea SP.) dapat menghasilkan $11 \%$ dari total ekspor hasil perkebunan Indonesia ke luar negeri (Dirjen Perkebunan, 2009). Akibatnya, pemerintah bekerja sama dengan petani untuk memberikan instruksi dan pengembangan pertanian melalui asosiasi petani yang membantu produsen kopi. Konsep bergabung 
dengan kelompok muncul dari kesadaran bahwa tidak ada orang yang dapat memenuhi semua keinginan dan harapan mereka sendiri. Dalam hal memenuhi kebutuhan mendasar mereka sendiri untuk makanan, perumahan, dan keamanan, banyak orang, terutama dalam masyarakat kontemporer, merasa tidak mampu, kekurangan energi, waktu, dan tenaga.

Desa Simpang Talang Tembago berada di Kecamatan Jangkat Timur yang meruapakan bagian dari Kabupaten Merangin adalah satu-satunya desa yang pertama kali berhasil dari kelompok taninya yang telah mempunyai produksi kopi bubuk kemasan dan telah beberapa kali menang saat perlombaan ataupun acara lainnya yang telah dinobatkan menjadi kopi terbaik se-Indonesia yaitu kelompok tani KWT Usaha Bunda Setinjau Alam. Hal tersebut mengindikasikan bahwa kelompok tani dapat memberikan manfaat bagi wanita tani dalam berbagai hal. Peran kelompok tani sebagai kelas pembelajaran yang dominan dan untuk meningkatkan produksi serta nilai tambah kopi (Arini et al., 2018); (Parawansa et al., 2018); (Maulana, 2019); (Puryantoro, 2021). Peran kelompok tani dapat meningkatan pendapatan petani tergolong tinggi (Prasetia et al., 2015); (Mawarni et al., 2017). Peran kelompok tani juga memiliki hubungan yang signifikan dengan peningkatan status sosial serta peran wanita tani (Salam et al., 2017); (Fyka \& Arif, 2017); (Fibrianingtyas et al., 2022). Peran kelompok dapat meningkatkan pengetahuan perempuan tani serta sarana pertanian (Nuryanti \& Swastika, 2016); (Ningsih et al., 2019); (Arianti et al., 2021)

Tidak semua petani kopi di Desa Simpang Talang Tembago menjadi anggota kelompok tani KWT Usaha Bunda Sitinjau dikarenakan kelompok tani ini masih dalam proses pengembangan dan juga dikarenakan masyarakat petani kopi yang lainnya banyak yang telah mencoba memproduksi kopi sendiri sehingga dalam penelitian ini menjadi kajian yang menarik peneliti untuk melihat bagaimana peran kelompok yang beranggotakan petani beruapaya meningkatkan pendapatan petani khususnya petani kopi dan bagaimanakah pendapatan kelompok tani kopi di lokasi Penelitian.

\section{MATERI DAN METODE}

Penelitian ini dilaksanakan di Desa Simpang Talang Tembago Kecamatan Jangkat Timur Kabupaten Merangin Provinsi Jambi. Pemilihan lokasi ini dilakukan dengan sengaja (purposive) dengan pertimbangan bahwa Desa Simpang Talang Tembago sebagai salah satu sentral dan pengembangan pertanian di sektor perkebunan kopi di Kabupaten Merangin Provinsi Jambi, dan satu-satunya desa yang memiliki Kelompok Tani yang berperan penting saat dinobatkan sebagai Produk kopi terbaik se-Indonesia pada saat di event International Coffee day 2019 dan pernah mendapatkan penghargaan rasa kopi terbaik di acara $7^{\text {th }}$ Scai Micro Lost Coffee Auction 2018. Penelitian ini di laksanakan pada tanggal 1 Juli 2020 sampai 30 Juli 2020.

Data primer mengacu pada informasi tangan pertama yang dikumpulkan oleh peneliti tentang faktor-faktor yang relevan dengan tujuan khusus penelitian. Responden individu, kelompok fokus, dan jika kuesioner disampaikan melalui internet, internet juga dapat menjadi sumber data utama (Sekaran, 2006). Wawancara dengan responden yang dipimpin dengan seperangkat pertanyaan (kuesioner) yang telah disiapkan terlebih dahulu memberikan data primer. Anggota kelompok tani KWT Usaha Bunda Setinjau Alam yang membantu budidaya kopi di Desa Simpang Talang Tembago, Kecamatan Jangkat Timur, Merangin, diwawancarai. Data yang diperoleh dari sumber yang ada disebut sebagai data sekunder. Catatan atau dokumen perusahaan, surat kabar pemerintah, analisis industri media, studi masa lalu, internet, dan sebagainya adalah contoh sumber data sekunder (Sekaran, 2006). Data sekunder dikumpulkan dari berbagai sumber, termasuk dinas perkebunan, dinas tanaman pangan dan hortikultura, Balai Penyuluhan Pertanian BPS, dan berbagai media terkait petani.

Pendekatan survei digunakan dalam penelitian ini, yang mengharuskan peneliti memilih responden dari satu populasi dengan menggunakan kuesioner sebagai instrumen pengumpulan data. Dan penyelidikan ini difokuskan pada suatu hal tertentu (Studi Kasus). Sasaran penelitian dalam penelitian ini adalah kelompok tani KWT Usaha Bunda Setinjau Alam di Desa Simpang Talang Tembago Kecamatan Jangkat Timur Kabupaten Merangin yang merupakan kelompok tani penghasil Kopi D'Jangkat Sungai Tenang yang beberapa kali mendapatkan penghargaan sebagai Kopi. Pada acara 7thScai Micro Lost Coffee Auction 2018 di Bali dan pada acara International Coffee Day 2019, perwakilan terbesar Provinsi Jambi. Jumlah responden dalam penelitian ini adalah 24 orang yang seluruhnya merupakan anggota Kelompok Tani KW Usaha Bunda Setinjau Alam.

Purposive sampling, atau pengambilan sampel berdasarkan faktor-faktor yang berkonsentrasi pada tujuan tertentu daripada acak, geografis, atau strata, digunakan untuk memilih responden dalam penelitian ini (Arikunto, 2006). Penentuan responden dalam penelitian ini didasarkan pada prestasi Kelompok Tani KWT Usaha Bunda Setinjau Alam. 
Peran kelompok tani dalam meningkatkan pendapatan petani kopi di desa Simpang Talang Tembago Kecamatan Jangkat Timur Kabupaten Merangin ditentukan dengan penilaian Skala Likert yang membagi ketiga indikator tersebut menjadi beberapa item pertanyaan yang telah disusun dalam angket dan memberikan tugas. skor untuk setiap item pertanyaan berdasarkan pilihan. Ada total 24 responden, yang masing-masing ditanyakan 15 pertanyaan. level 1 (tidak pernah), level 2 (kadangkadang), dan level 3 (selalu) (selalu).

Metode berdasarkan Sudjana (2001) akan digunakan untuk menghitung skor penelitian berdasarkan kriteria menurut skala Likert. Hasil penghitungan tersebut digunakan untuk menentukan peranan kelomok tani dalam peningkatan pendapatan petani kopi di lokasi penelitian yang di kategorikan menjadi dua yaitu skor 720 - 1080 Tinggi dan skor 360 - 719 Rendah

Analisis data untuk mengetahui pendapatan kelompok tani kopi KWT Usaha Bunda Setinjau Alam di lokasi penelitian dilakukan dengan analisis skala likert. setiap item pertanyaan diberikan skor sesuai dengan pilihan responden dengan total 24 orang dan masing-masing di beri 8 pertanyaan. jenjang 1 (tidak setuju), 2 (ragu-ragu), 3 (setuju).

Skor penelitian berdasarkan criteria menurut skala likert ini akan diperoleh dengan rumus berdasarkan Sudjana (2001). Hasil penghitungan tersebut digunakan untuk menentukan tinggi rendahnya pendapatan petani kopi di lokasi penelitian yang di kategorikan menjadi dua yaitu skor 336 - 504 Tinggi dan skor 168 - 335 Rendah

\section{HASIL DAN PEMBAHASAN}

\section{Peranan KWT Usaha Bunda Setinjau Alam Dalam Peningkatan Pendapatan Petani Kopi}

Peranan KWT Usaha Bunda Setinjau Alam dalam peningkatan pendapatan petani kopi di lokasi Penelitian dapat diketahui dengan 3 peranan penting kelompok tani yaitu, (1). Media sosial atau media penyuluhan yang bersifat live, natural, dan dinamis. (2) Instrumen yang digunakan penyuluh pertanian untuk melakukan perubahan. (3). Sebuah ruang atau wadah untuk mengekspresikan aspirasi yang bersih dan sehat, seperti yang diungkapkan oleh petani itu sendiri.. Dari 3 peranan tersebut maka di sebarkan kuesioner atau pertanyaan dengan masing - masing peranan diberikan 5 pertanyaan dengan total 15 pertanyaan kepada 24 responden.Masing-masing pertanyaan di berikan skor penilaian jawaban selalu (3), kadang-kadang (2), Tidak pernah (1). Untuk lebih jelasnya dapat dilihat pada Tabel 1 berikut ini.

Tabel 1. Sebaran skor perananan KWT Usaha Bunda Setinjau Alam dalam peningkatan pendapatan petani kopi

\begin{tabular}{rrcc}
\hline No & Kategori & Jumah (orang) & Persentaase $(\%)$ \\
\hline 1. & Tinggi $(720-1080)$ & 24 & 100 \\
2. & Rendah $(360-719)$ & 0 & 0 \\
\hline & Total & 24 & $100 \%$ \\
\hline
\end{tabular}

Sumber : Data Primer Diolah, 2020

Dapat dilihat pada Tabel 1 di atas, peran kelompok tani dihitung dari jumlah skor dari jawaban kuesioner pertanyaan ketiga peran kelompok tani, maka didapatkan dengan total skor jawaban sebanyak 1035 dan itu menjelaskan bahwa kelompok tani berperan tinggi dalam peningkatan pendapatan.

Adapun peran pertama yaitu sebagai (1) Media sosial atau media penyuluh yang hidup, wajar, dan dinamis memperoleh skor sebanyak 360,' itu di buktikan dengan pertanyaan yang di jawab degan kenyataanya para anggota Kelompok Wanita Tani (KWT) Usaha Bunda Setinjau Alam Kecamatan Jangkat Timur Kabupaten Merangin selalu belajar dan berinovasi untuk meningkatkan keterampilan berusaha tani kopi di daerahnya,Kelompok Wanita Tani ini juga menyampaikan dan mensosialisasikan tentang cara pemakaian alat dan teknologi pengolahan kopi yang baik dan benar melakukan diskusi dengan sesama anggota dan menjalin kerjasama (mitra) dengan Instansi/pihak lainnya untuk mempermudah dalam usaha tani kopi.

Peran kelompok tani selanjutnya yaitu sebagai (2) Alat untuk mencapai perubahan dengan tujuan penyuluh pertanian yang memperoleh skor sebanyak 319 dapat dilihat dari hasil atau jawaban yang diberikan dan tentunya ini menjadikan kelompok tani ini mempunyai peran penting, itu terjadi kerena Kelompok Wanita Tani Usaha Bunda Setinjau Alam selalu menjadi peran perantara penyaluran dana ataupun sarana produksi yang sesuai dengan kebutuhan petani yang mereka dapatkan dari bantuan pemerintah, selalu menggerakkan petani untuk meningkatkan keterampilan dalam berusaha tani kopi, berusaha yang terbaik memberikan pendampingan /pemantauan secara 
bersekala dalam peng-prosesan budidaya kepada petani dan membantu petani mendapatkan keuntungkan, kelompok Wanita Tani ini juga membantu masyarakat dalam memasarkan hasil panen.

Peran kelompok tani terakhir yaitu sebagai (3) Tempat pernyataan aspirasi sesuai yang diinginkan petani yang memperoleh skor sebanyak 356. terjawab karena Kelompok Wanita Tani Usaha Bunda Setinjau Alam selalu bebas dalam menyampaikan pendapat dan menerima saran dan kritikandari Petani dan juga dalam sesama anggota kelompok tani, para anggotanya juga selalu berusaha mengikuti penjelasan dan sejenis seminar yang berkaitan tentang inovasi bidang pertanian yang diadakan dan disampaikan penyuluh atau kelompok tani dari awal sampai akhir,mereka juga selalu mengadakan pertemuan rutin dan melakukan diskusi untuk memilah aspirasi-aspirasi, usulan, keinginan atau kehendak dari para anggota kelompok tani. Dalam penelitian Kholik et al. (2017) menyatakan bahwa berbagi pengetahuan, kolaborasi, peningkatan motivasi, dan modifikasi perilaku adalah semua elemen sosial yang mempengaruhi pendapatan petani kacang panjang di Tabir Lintas Kabupaten Merangin, sehingga pendapatan juga terpengaruh.

\section{Tingkat Pendapatan KWT Usaha Bunda Setinjau Alam}

Tingkat pendapatan KWT Usaha Bunda Setinjau Alam di Desa Simpang Talang Tembgo Kecamatan Jangkat Timur Kabupaten Merangin dilakukan dengan analisis Skala Likert dengan cara menyebarkan kuesioner atau pertanyaan mengenai pendapatan dengan total 8 pertanyaan kepada 24 responden. Masing-masing pertanyaan di berikan skor penilaian jawaban setuju (3), ragu-ragu (2), Tidak setuju (1).Untuk lebih jelasnya dapat dilihat pada Tabel 2 berikut ini.

Tabel 2. Sebaran skor tingkat pendapatan KWT Usaha Bunda Setinjau Alam

\begin{tabular}{cccc}
\hline No & Kategori & Jumah (orang) & Persentaase $(\%)$ \\
\hline 1. & Tinggi $(384-576)$ & 24 & 100 \\
2. & Rendah $(192-383)$ & 0 & 0 \\
\hline & Total & 24 & $100 \%$ \\
\hline
\end{tabular}

Sumber : Data Primer Diolah, 2020

Dapat dilihat pada Tabel 2 di atas reponden yang menjawab pertanyaan sebaran kuesioner pendapatan kelompok tani dari 24 responden dengan skor jawaban yang didapatkan tinggi yaitu sebanyak 505, pendapatan yang mereka peroleh setelah menjadi anggota Kelompok Wanita Tani Usaha Bunda Setinjau Alam lebih tinggi jika dibandingkan dengan ketika mereka tidak menjadi anggota, mereka juga tidak lagi kekurangan dalam segi ekonomi rumah tangga, sudah tidak bergantung lagi kepada suami untuk memenuhi kebutuhan pribadinya, bisa rutin menabung, bisa membayar tagihan cicilan kredit pinjaman, bisa membiayai sekolah anak-anaknya, bisa membantu kepala keluarga memenuhi kebutuhan keluarga, dan bisa mengembangkan usahanya, semua iu didapatkan dan peroleh dari begabungnya mereka menjadi anggota Kelompok Wanita Tani Setinjau Alam, mereka bisa menukarkan ide dan inovasi dalam usaha produk kopi, baik dari pembuatan produk yang mereka produksi yaitu kopi bubuk D'Jangkat Sungai Tenang yang di pasarkan dengan berbagai parian ukuran dan tentunya dengan kualitas terbaik, mereka juga menjual kopi biji hitam yang siap di giling yang biasanya di jual dalam jumlah perkilogram serta kerja sama yang dilakukan dengan beberapa kelompok lain atau instansi lain dalam usahanya dan mereka pun bisa lebih mudah dalam memasarkan produknya, pada penelitian Fikriman et al. (2020)menyatakan bahwa pendapatan, pendidikan ibu rumah tangga, jumlah anggota keluarga, dan dukungan sosial untuk makanan semuanya berdampak pada pengeluaran makanan keluarga miskin, sehingga pendapatan mempengaruhi pendapatan masyarakat secara keseluruhan.

\section{KESIMPULAN DAN SARAN}

Berdasarkan temuan, KWT Usaha Bunda Setinjau Alam memiliki peran signifikan dalam meningkatkan pendapatan petani kopi di desa Simpang Talang Tembago, Kecamatan Jangkat Timur, Kabupaten Merangin, dengan skor 1035 dari 720-1080. Di Desa Simpang Talang Tembago Kecamatan Jangkat Timur Kabupaten Merangin Tinggi Kelompok Tani KWT Bunda Setinjau Alam memiliki tingkat pendapatan 505 dengan kategori tinggi 384-576. Penulis menyarankan kepada Kelompok Tani KWT Bunda Setinjau Alam untuk memperluas pemasaran barang Kopi D'Jangkat Sungai Tenang, berdasarkan temuan penelitian, karena pemasaran yang terfokus saat ini masih kurang. Pemerintah Kabupaten Merangin diharapkan memberikan perhatian lebih kepada semua usaha pertanian, baik dari organisasi maupun agroindustri, khususnya yang menyangkut barangbarang pertanian. 


\section{REFERENSI}

Arianti, F., Taridala, S. A. A., \& Sadimantara, F. N. (2021). Participation of Women Farmers Group Members on Pekarangan Pangan Lestari (P2L) Program In Kendari City Southeast Sulawesi. International Journal of Agricultural Social Economics and Rural Development (ljaserd), 1(2), 56. https://doi.org/10.37149/ijaserd.v1i2.20210

Arikunto. (2006). Prosedur Penelitian Suatu Pendekatan Praktek. PT. Rineka Cipta.

Arini, A. A., Arimbawa, P., \& Abdullah, S. (2018). Konawe, Peran Kelompok Tani dalam Usahatani Padi Sawah (Oryza sativa L) di Desa Belatu Kecamatan Pondidaha Kabupaten. Jurnal IImiah Membangun Desa Dan Pertanian, 3(1), 16-22. https://doi.org/http://dx.doi.org/10.33772/jimdp.v3i1.6800

Fibrianingtyas, A., Pertiwi, V. A., \& Rayesa, N. F. (2022). The Effectiveness of Facilitator's Role in Sustainable Farmer Community Empowerment. International Journal of Agricultural Social Economics and Rural Development (ljaserd), 2(1), 13-20. https://doi.org/http://dx.doi.org/10.37149/ijaserd.v2i1.21711

Fyka, S. A., \& Arif, L. O. K. (2017). Kajian Kelembagaan dan Pemberdayaan Masyarakat Pesisir Kawasan Daerah Perlindungan Laut Masyarakat di Kabupaten Wakatobi. Buletin Penelitian Sosial Ekonomi Pertanian Fakultas Pertanian Universitas Haluoleo, 19(37), 128-139. https://doi.org/http://dx.doi.org/10.33772/bpsosek.v19i37.5821

Fikriman, F., Budiman, F. A., \& Afrianto, E. (2020). Faktor Sosial Ekonomi yang Mempengaruhi Pengeluaran Pangan Rumah Tangga Miskin di Kecamatan Bangko Kabupaten Merangin. Jurnal Agri Sains, 4(2)(149-161).

Hasan, I. (2011). Penguatan Kompetensi Kewirausahaandan Daya Saing UKM Komoditi Unggulan Ekspor. Jurnal Infokop Provinsi Aceh.

Kholik, A., Susilawati, W., \& Fikriman, F. (2017). Pengaruh Faktor Sosial Dalam Kelompok Tani Terhadap Pendapatan Usahatani Kacang Panjang (Vigna Sinensis L) di Kecamatan Tabir Lintas Kabupaten Merangin. Jurnal Agri Sains, 1(2).

Maulana, K. (2019). Peran Kelompok Tani Terhadap Kondisi Perekonomian Petani. Jurnal Pendidikan Teknologi Pertanian, 5(2), 61-66.

Mawarni, E., Buruwadi, M., \& Bempah, I. (2017). Peran kelompok tani dalam peningkatan pendapatan petani padi sawah di desa iloheluma kecamatan tilongkabila kabupaten bone bolango. Agrinesia, 2(1), 65-73.

Ningsih, N., Nalefo, L., \& Wunawarsih, I. A. (2019). Efektivitas Metode Kelompok terhadap Peningkatan Pengetahuan Wanita Tani dalam Pemanfaatan Lahan Pekarangan di Desa Kalimas Kecamatan Kaledupa Kabupaten Wakatobi. Jurnal Ilmiah Membangun Desa Dan Pertanian, 4(2), 47-51. https://doi.org/http://dx.doi.org/10.33772/jimdp.v4i2.6659

Nuryanti, S., \& Swastika, D. K. S. (2016). Peran Kelompok Tani dalam Penerapan Teknologi $\begin{array}{llll}\text { Pertanian. Forum Penelitian Agro } & 115 .\end{array}$ https://doi.org/10.21082/fae.v29n2.2011.115-128

Parawansa, D., Arimbawa, P., \& Salahuddin. (2018). Peranan Kelompok Tani dalam Usahatani Kakao di Desa Lambandia Kecamatan Lambandia Kabupaten Kolaka Timur. Jurnal IImiah Membangun Desa Dan Pertanian, 3(6), 157-162. https://doi.org/http://dx.doi.org/10.33772/jimdp.v3i6.7983

Perkebenunan, D. J. (2009). Volume dan Nilai Ekspor, Impor Indonesia. Departemen Pertanian.

Prasetia, R., Hasanuddin, T., \& Viantimala, B. (2015). Peranan Kelompok Tani dalam Peningkatan Pendapatan Petani Kopi di Kelurahan Tugusari Kecamatan Sumberjaya Kabupaten Lampung Barat. Jurnal IImu-IImu Agribisnis (JIIA), 3(3), 301-307.

Puryantoro, P. (2021). Analisis Nilai Tambah Pengolahan Kopi Arabika Di Kelompok Tani Sejahtera Kabupaten Situbondo. Jurnal IImiah Membangun Desa Dan Pertanian, 6(1), 1. https://doi.org/10.37149/jimdp.v6i1.16139

Salam, I., Salahuddin, S., \& Saputra, I. (2017). Peranan Kelompok Tani dalam Peningkatan Status Sosial Petani Padi Sawah di Desa Meraka Kecamatan Lambuya Kabupaten Konawe. Buletin Penelitian Sosial Ekonomi Pertanian Fakultas Pertanian Universitas Haluoleo, 19(37), 139147. https://doi.org/http://dx.doi.org/10.33772/bpsosek.v19i37.5822

Sekaran, U. (2006). Prosedur Penelitian Suatu Pendekatan Praktek. PT. Rineka Cipta.

Sudjana. (2001). Metode Statistik. Tarsito. 